\title{
THE COMPARATIVE STUDY OF STANDARD MACINTOSH HANDLE VERSUS SHORT HANDLE FOR LARYNGOSCOPY AND INTUBATION IN OBSTETRIC PATIENTS FOR LOWER SEGMENT CESAREAN SECTION
}

Neeharika $^{1}$

\section{HOW TO CITE THIS ARTICLE:}

Neeharika. "The Comparative Study of Standard Macintosh Handle versus Short Handle for Laryngoscopy and Intubation in Obstetric Patients for Lower Segment Cesarean Section". Journal of Evolution of Medical and Dental Sciences 2014; Vol. 3, Issue 45, September 18; Page: 11080-11089, DOI: 10.14260/jemds/2014/3446

ABSTRACT: INTRODUCTION: The incidence of failed intubation is higher in obstetrics (1:280) than other surgical patients (1:2230). The anatomical factors that place the pregnant patient at increased risk for airway complications and difficult intubation include pregnancy induced generalized weight gain particularly increase in breast size, respiratory mucosal edema, and an increased risk of pulmonary aspiration. In the supine position, the enlarged breasts tend to fall back against the neck, which can interfere with insertion of the laryngoscope. The aim of our study is to assess the efficacy of short handle laryngoscope versus standard Macintosh handle laryngoscope for laryngoscopy and intubation in obstetric patients posted for Lower Segment Cesarean Section. PLAN OF STUDY: Randomized prospective study. ASA grade I and II full term obstetric patients posted for elective or emergency LSCS studied in two groups[ Group I ( $n=20)$ - Standard Macintosh handle, Group II ( $n=20)$

- Short / stubby handle (Anesthetics make, India)]. Height and weight of patients were recorded. Head, neck and oral cavity of the patient were examined to rule out any obvious pathology and to detect any anticipated difficult intubations for exclusion. Examination of the airway included: neck length, sternomental distance, thyromental distance, inter incisor gap, chest circumference and modified Mallampati grading. The observations noted during laryngoscopy: number of attempts for insertion of laryngoscope into oral cavity, ease of insertion of laryngoscope blade into oral cavity, number of attempts for successful intubation, duration of laryngoscopy and intubation, perpendicular distance from the lower edge of distal end of laryngoscope handle to patient's chest wall. OBSERVATIONS: The perpendicular distance was significantly higher in group II $(16 \mathrm{~cm})$ than group I $(13.6 \mathrm{~cm})$.The time for laryngoscopy and intubation hard a significant correlation to weight as well as chest circumference in group I, but not in group II. There was difficulty in insertion of laryngoscope handle in one patient of group I, due to enlarged breasts. Successful laryngoscopy could be performed in one attempt, but the time taken was longer (45s) as compared to the mean duration of laryngoscopy and intubation (16.65s) in the same group. No such difficulty was encountered in group II. CONCLUSION: Short handle provides more room for insertion of laryngoscope blade into patient's oral cavity; it's manipulation during laryngoscopy and application of cricoid pressure. Hence it makes laryngoscopy easier without any prolongation of time duration of laryngoscopy.

KEYWORDS: Short handle laryngoscope, obstetric, Cesarean Section.

INTRODUCTION: The incidence of failed intubation is higher in obstetrics than other surgical patients. The incidence was 1:280 in obstetric and 1:2230 in non-obstetric patients, ${ }^{11}$ as reported by Samsoon and Young. The principal adverse outcomes associated with the difficult airway include cerebral insult, permanent neurological damage, myocardial insult, airway trauma, and / or death. 
One of the principal factors associated with a difficult airway in obstetric patients was increased chest circumference due to enlarged breasts which hampered the insertion of laryngoscope during intubation. 6,8 Modifications in the technique for laryngoscopy like inserting the laryngoscope with handle turned towards right, subsequently rotating to sagittal plane were suggested to circumvent this problem. ${ }^{10}$

Another technique suggested was to insert the laryngoscope blade first and then attach the handle to the blade. ${ }^{9}$ The laryngoscope design was modified to increase the angle between the laryngoscope handle and blade or the use of Howland lock so that the handle stayed clear of patient's chest.6,7 The pediatric handle may be used during laryngoscopy to provide more room between the end of handle and breasts. ${ }^{3}$

In 1981, Dutta and Briwa ${ }^{2}$ reduced the length of laryngoscope handle, to facilitate the introduction of laryngoscope blade and used it in obstetric patients. Though there are a lot of designs of laryngoscope blades to serve the purpose of laryngoscopy, as on today there are only three types of laryngoscope handles in practice.

The randomized prospective study titled 'The study of standard Macintosh handle versus short handle for laryngoscopy and intubation in obstetric patients for Lower Segment Cesarean Section' was conducted from May 2005 to November 2006 at Department of Anesthesiology, Government Medical College and hospital, Nagpur, Maharashtra. Institutional Ethical committee approval was obtained for the study.

\section{AIMS:}

- To assess the efficacy of short handle laryngoscope versus standard Macintosh handle laryngoscope for laryngoscopy and intubation in obstetric patients posted for Lower Segment Cesarean Section.

- To compare the ease of laryngoscopy and intubation with short handle versus standard Macintosh handle.

- Merits and demerits of short handle versus standard handle.

METHODS: The subjects were ASA I \& II full term obstetric patients posted for elective or emergency Lower Segment Cesarean Section. Patients were divided randomly into two groups.

Group I: $(n=20)$ - Standard Macintosh handle.

Group II: (n=20) - Short / stubby handle (Anesthetics make, India).

Exclusion criteria for the study were- ASA grade III and IV, eclampsia, heart disease, acute Fetal distress (F.H.S. $<100 / \mathrm{min}$ ), no consent, full stomach patients.

Checklist of instruments / equipment beforehand- Anatomical masks size 3 \& 4, Guedel or pharyngeal airway size 3 \& 4,Nasopharyngeal airway size 7, Laryngoscope Macintosh standard handle, Short / stubby handle - Anesthetics, India make, Curved Macintosh blade 3 \& 4, Cuffed Endotracheal Tubes sizes 6, 6.5, 7, 7.5, Malleable stylets, Magill's forceps.

Each patient fulfilling the inclusion criteria, was explained the procedure. Written informed consent was taken, for general anesthesia. Demographic data, height, weight, BMI of patients were recorded. Head, neck and oral cavity of the patient were examined to rule out any obvious pathology and to detect any anticipated difficult intubation patients for exclusion. 
Specific examination of the airway included sternomental distance, thyromental distance, interincisor gap, neck length and mallampati score. In the operation theater, the patient was placed in supine position with head placed on a ring pillow (size- $22 \mathrm{~cm}$. external diameters, $11 \mathrm{~cm}$. internal diameters). Preoperative vital signs- pulse, Blood Pressure were noted. Monitors - E.CG, NIBP, pulse oximeter were attached to the patient.

An intravenous line was set up and preloading was done with $500 \mathrm{ml}$ of Ringer's Lactate was given intravenously. Patient was premeditated with intravenous I.V Rantidine $50 \mathrm{mg}$, I.V Metoclopramide $10 \mathrm{mg}$, I.V Glycopyrrolate $0.2 \mathrm{mg}$. Preoxygenated with $100 \%$ oxygen on mask for three minutes and Induced with i.v. Thiopentone $5 \mathrm{mg} / \mathrm{kg}$. Slowly. As soon as consciousness was lost, assistant was asked to apply external cricoid pressure. Ventilation on mask was confirmed and on loss of eyelash reflex, I.V. succinylcholine $2 \mathrm{mg} / \mathrm{kg}$. was administered.

Patient's head in 'sniffing the morning air' position, with neck slightly flexed and atlantoccipital joint maximally extended, laryngoscopy was performed using standard Macintosh handle with size 3 curved Macintosh blade in group I patients and short / stubby handle (Anesthetics India make) with size 3 Macintosh curved blade in group II patients. Patient's trachea was intubated with appropriate size xylocaine gel pre lubricated cuffed endotracheal tube.

Placement of endotracheal tube was confirmed by visualizing bilateral chest expansion, bilateral equal air entry into the chest, and manual feel of rebreathing bag. $\mathrm{SPo}_{2} \%$ was also noted immediately after endotracheal intubation. Cuff of the endotracheal tube was inflated, cricoid pressure released and endotracheal tube fixed.

Endotracheal tube was connected to the Bain's circuit and IPPV was given. Obstetrician was asked to start the surgical procedure. Maintenance of anesthesia was done using $50 \% \mathrm{~N}_{2} \mathrm{O}$ and $50 \%$ oxygen and IPPV till the extraction of the baby. After extraction of baby, 5 units oxytocin infusion was started, patient was sedated with IV Pentazocine $0.5 \mathrm{mg} / \mathrm{kg}$, IV Midazolam $0.04 \mathrm{mg} / \mathrm{kg}$. Later the anesthesia was maintained with $\mathrm{N}_{2} \mathrm{O}: \mathrm{O}_{2}$ (50:50) + Halothane $0.5-1 \%$ + IV Vecuronium (non depolarizing muscle relaxant) $0.08 \mathrm{mg} / \mathrm{kg}$ and IPPV.

At the end of surgery and on return of spontaneous respiration, inj. Neostigmine $2.5 \mathrm{mg}+\mathrm{inj}$. Glycopyrrolate $0.4 \mathrm{mg}$ was administered intravenously slowly for reversal of residual effect of muscle relaxant. On regaining consciousness, adequate motor reflexes, and adequate spontaneous respiration, extubation was done after oropharyngeal suction. Post-operative blood pressure, heart rate, respiratory rate were noted. Postoperative advice regarding nil by mouth period, drugs and I.V fluids were noted and conveyed to the obstetrician.

Observations noted during laryngoscopy-number of attempts required for insertion of laryngoscope into oral cavity, ease of insertion of laryngoscope blade into patient's oral cavity with standard Macintosh handle and short handle, number of attempts for successful intubation, duration from introduction of laryngoscope blade into patient's oral cavity to successful intubation (Seconds), the perpendicular distance from the lower edge of distal end of laryngoscope handle to patient's chest wall (Centimeters) 
MEASUREMENT OF PERPENDICULAR DISTANCE BETWEEN LOWER END OF STANDARD MACINTOSH HANDLE AND PATIENT'S CHEST WALL

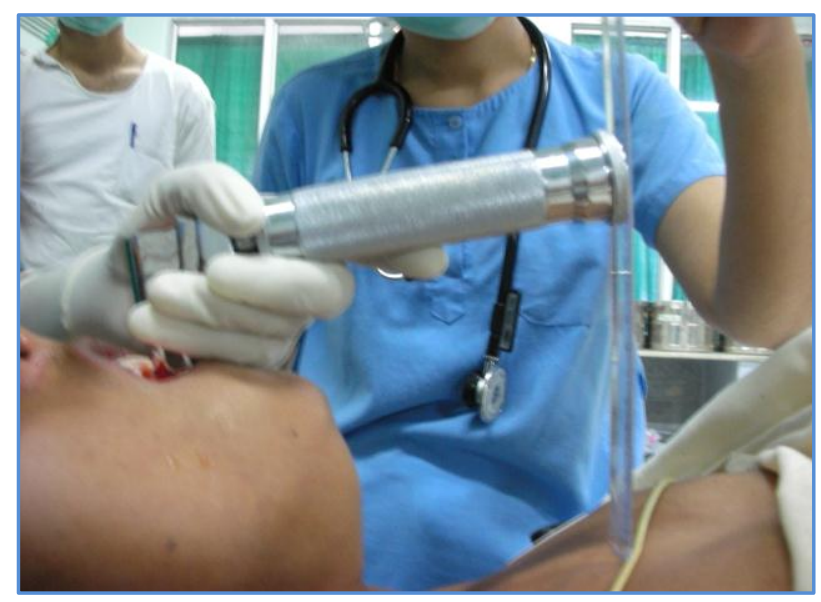

Figure 1

MEASUREMENT OF PERPENDICULAR DISTANCE BETWEEN LOWER END OF SHORT HANDLE AND PATIENT'S CHEST WALL

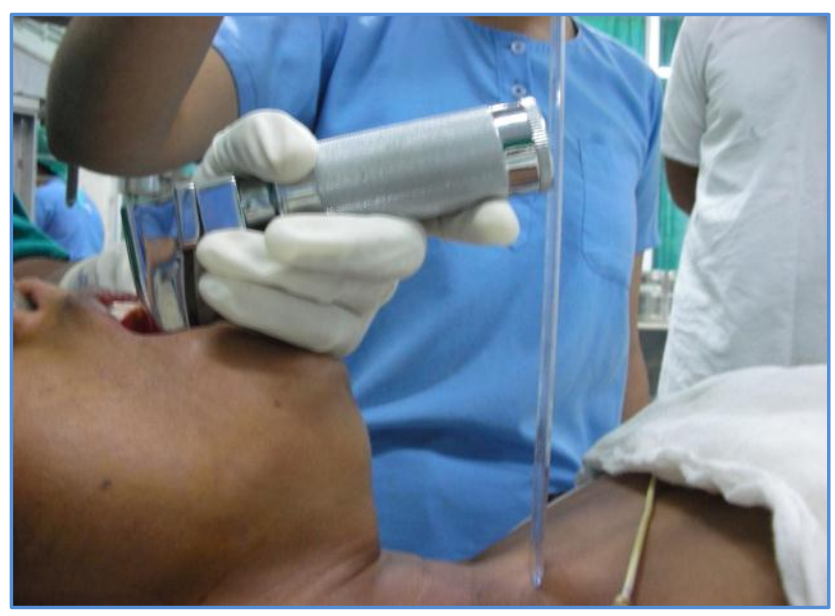

Figure 2

Categorical variables were expressed as percentages. Categorical data was analyzed by chi square test. For small numbers fisher exact test was applied. Continuous variables were expressed as mean ( \pm standard deviation). Unpaired $t$ test was used to compare differences between the two groups. Correlation between two variables was assessed by correlation coefficient ( $\mathrm{r}$ ). $\mathrm{p}<0.05$ was taken as statistical significance. Data was analyzed on statistical software STATA version 8.0.

RESULTS: The demographic parameters of the patients from both the groups were studied and compared. Most the patients (50\% in group I and 55\% in group II) belonged to the age group of 20 to 25 years. The mean weight of patients in group I was $52.45 \mathrm{~kg}$ (SD 3.83) and that in group II was 
$57.15 \mathrm{~kg}$ (SD 3.01). No significant difference was found between the two groups with respect to age and weight ( $\mathrm{p}$ value 0.1920 and 0.0942 respectively).

The chest circumference of the patients in both groups was studied and compared. No significant difference was found between the two groups for chest circumference. In group I, 25\% of patients had chest circumference $>90 \mathrm{~cm}$. whereas in group II, $35 \%$ patients had chest circumference $>90 \mathrm{~cm}$. This difference was found not be statistically significant ( $p$ value 0.4762 )

The various airway parameters in the two groups were compared. No statistical significant difference was found between the two groups for airway parameters. The correlation between weight and various airway parameters was assessed. There was no significant correlation of weight with neck length, thyromental distance, steromental distance or inter incisor gap.

There was significant correlation between weight and chest circumference in group I $(p=0.0491)$ and group II $(p=0000)$. This correlation was stronger in group II. As weight increases, the chest circumference also increases. The correlation of chest circumference and various airway parameters was studied. It was found to be not significant.

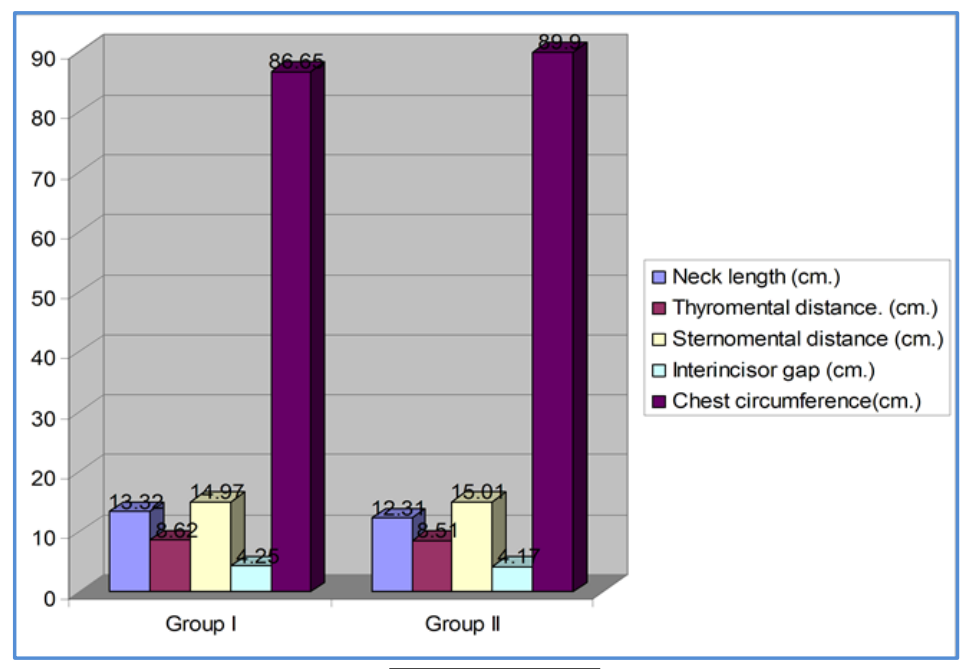

Graph 1

AIRWAY PARAMETERS: The mean number of attempts required for laryngoscopy was 1 in group I as well as in group II. Only one patient in group I posed a difficulty in insertion of laryngoscope blade into the oral cavity due to large breasts. The chest circumference in this patient was $100 \mathrm{~cm}$. The laryngoscope could be manipulated for insertion into the oral cavity in this patient without the need for second attempt. The time required for intubation (45 sec) was more than the mean duration of laryngoscopy in this group (16.65 seconds). No such difficulty was encountered in group II.

The mean number of attempts required for intubation was 1.05 (SD 0.22) in group I and 1 (SD 0 ) in group II. One patient in group I required two attempts for intubation due to inadequate relaxation of vocal cords. There was no difficulty in laryngoscopy and the Cormack Lehane laryngoscopic view was grade 1 . The mean time for laryngoscopy/intubation was $16.65 \mathrm{~s}$ (SD 7.02) in group I and 16 s (SD 6.13) in group I. There was no statistically significant difference between the two groups in this regard. 


\section{ORIGINAL ARTICLE}

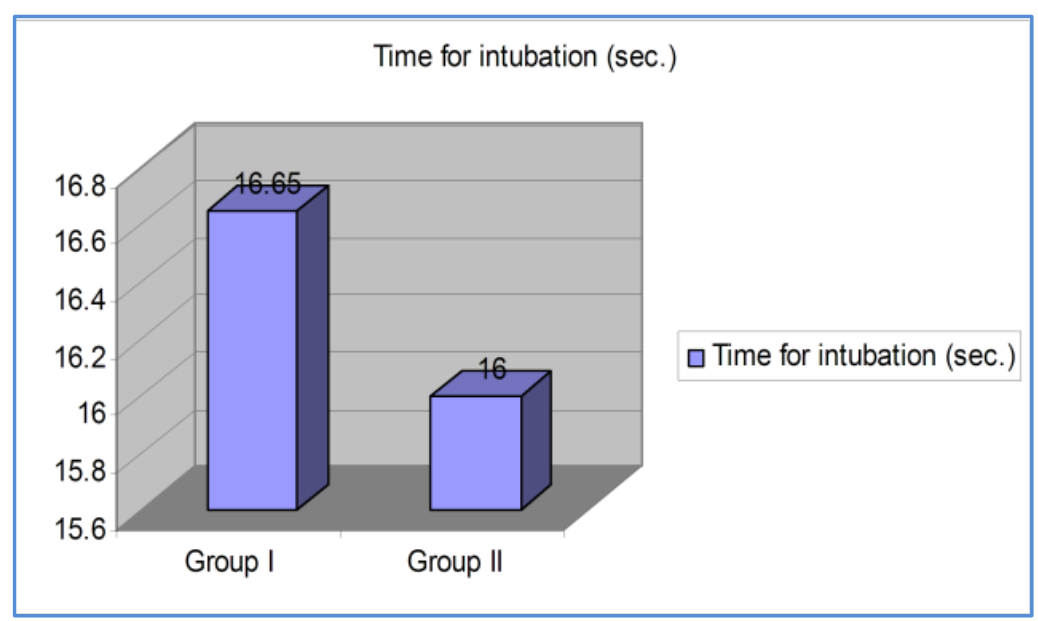

Graph 2

The perpendicular distance between the lower edge of distal end of laryngoscope handle and the patient's chest wall was assessed as a measure of room between the laryngoscope handle and the patient's chest. There was a highly significant difference between the two groups for this parameter (p-0.000). The mean distance was $16.25 \mathrm{~cm}$ (SD 1.94) in group II, significantly higher than $13.6 \mathrm{~cm}$ (SD 1.04) as found in group I. We found that the short handle allows more room for insertion of laryngoscope, and application of cricoid pressure, in comparison to the standard Macintosh handle.

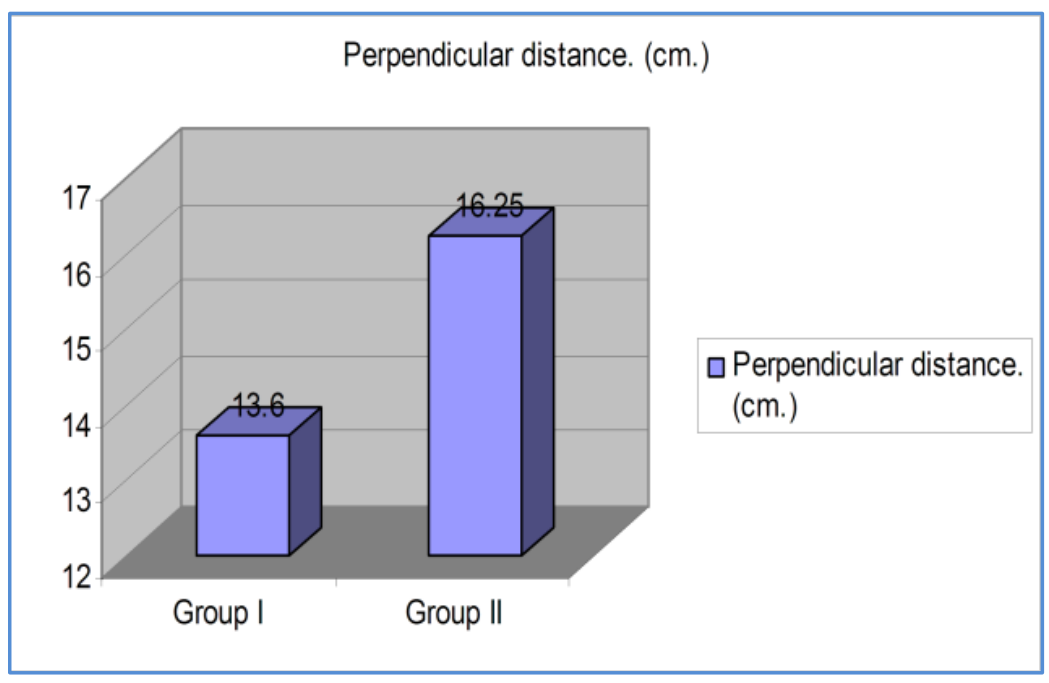

Graph 3

Also, the ease of inserting the laryngoscope blade into the oral cavity was subjectively more with the short handle as compared to the standard Macintosh handle. The time required for laryngoscopy and intubation had a significant correlation with the chest circumference in group I (p0.0213) with increased duration of laryngoscopy as chest circumference increases. No such correlation was found in group II short handle (p-0.2071). 


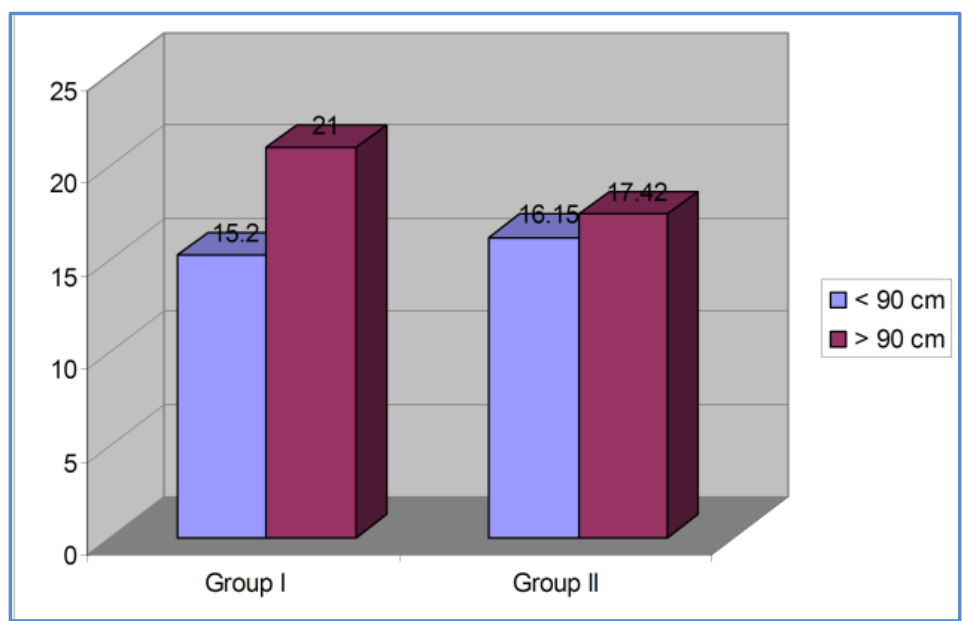

Graph 4

There was a significant correlation between the time required for laryngoscopy and weight of the patient ( $\mathrm{p}-0.0295)$ in group I. No such correlation was found in group II (p-0.4780). The time required for intubation did not increase significantly with increase in weight of the patient, with the use of short handle.

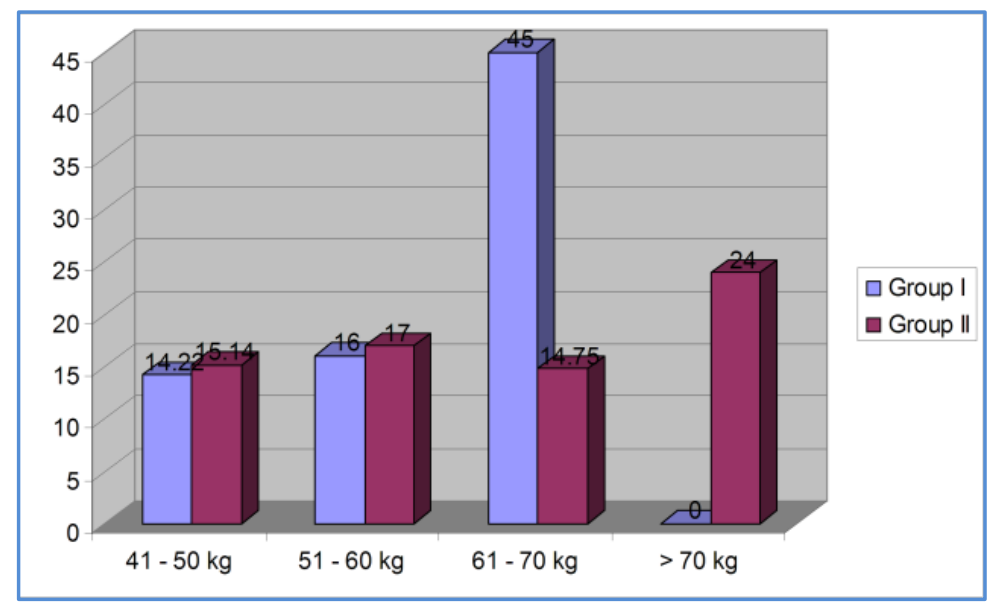

Graph 5

During this study, we did not come across a unanticipated difficult airway situation requiring change of laryngoscope handle or blade or requiring other airway equipment like stylet, Magill's forceps.

DISCUSSION: This study compared the efficacy of two diriment types of laryngoscope handles for intubation in obstetric patients. One of the various factors for difficult airway in obstetric patients has been identified as large breasts, in various studies. Dutta \& Briwa devised the short handle and used it in five patients. ${ }^{2}$

Other ways to circumvent the same problem were suggested as use of pediatric handle by Kay $\mathrm{NH},{ }^{3}$ or modifying the technique of laryngoscopy as, by rotating the handle in sagittal plane by Yukio 
Kubota, ${ }^{4}$ detaching the blade from laryngoscope handle during its insertion by Gandhi and Burgeos, ${ }^{9}$ and the use of anaesthesia adjustable handle.7 Successful laryngoscopy was possible with either type of laryngoscope handle. The insertion of laryngoscope into patient's oral cavity was found to be easier with short handle than standard Mc intosh handle.

This was due to greater space provided by the short handle, to maneuver the laryngoscope blade into patient's oral cavity as signified by the perpendicular distance between the lower edge of distal end of laryngoscope handle and the patient's chest wall which was $16.25 \mathrm{~cm}$ (SD 1.94) with the use of short handle, as compared to13.6 cm (SD 1.04) with standard Mc intosh handle.

The efficiency of the short handle was reflected in significantly less time required for intubation with the short handle $16.65 \mathrm{~s}$ (SD 7.02) vs16 s (SD 6.13) as well as number of attempts required for laryngoscopy. We faced a difficulty in insertion of laryngoscope blade with standard Macintosh handle, in one patient, resulting in a longer time for intubation.

CONCLUSION: During laryngoscopy, insertion of laryngoscope with short handle is much easier as compared to standard Macintosh handle. Due to ease of insertion of laryngoscopy, time factor of laryngoscopy and intubation is significantly reduced. Due to its advantage of providing more space for insertion of laryngoscope blade into patient's oral cavity without any increase in duration of laryngoscopy, the short handle laryngoscope may have a place among routine airway equipment for obstetric general anesthesia.

This will allow the anesthesiologist to develop a skill for use of short handle in routine cases, and its application in difficult airway situations due to heavy breasts and increased chest circumference. Though we came across difficulty in intubation in only $5 \%$ cases in group I and none in group II, we studied only Indian race at Nagpur district and around. This type of study is a must with races of different places and origins, including a larger number of patients.

It is always better be safe than sorry in a difficult airway situation. A well trained and well prepared anesthesiologist may be the lifesaving factor in a difficult airway situation, especially in obstetric patients. At each anesthetic center anesthesiologist and the other operation theatre personnel should strictly follow the airway management protocol. The operation theatre must have regular and special anesthetic devices and airway equipment to safeguard patient's life.

\section{REFERENCES:}

1. Brock Utne JG, Downing JW, Seedal F: Laryngeal oedema with preeclamptic toxemia. Anaesthesia 1977; 32: 556-558.

2. Dutta S, Briwa J: Modified laryngoscope for endotracheal intubation of obese patients. Anaesthesia and Analgesia 1981; 60 (2): 120-121.

3. Kay NH: Mammomegaly and intubation. Anaesthesia 1982; 37: 221.

4. Kubota Yukio: Mammomegaly and intubation. Anaesthesia 1982; 37: 779.

5. Cormack R. S, Lehane J: Difficult tracheal intubation in obstetrics. Anaesthesia 1984; 39: 11051111.

6. Jellicoe JA, Harris NR: A modification of standard laryngoscope for difficult tracheal intubation in obstetrics. Anaesthesia 1984; 39: 80-82.

7. Patil VU, Stehling Linda, Zauder Howard: An adjustable laryngoscope handle for difficult intubations. Anaesthesiology 1984; 60: 609. 


\section{ORIGINAL ARTICLE}

8. Lyons G; Failed intubation-six years' experience in a teaching maternity unit. Anaesthesia 1985; 40: 759-762.

9. Gandhi S, Burgos L: A technique of laryngoscopy for difficult intubation. Anaesthesiology 1986; 64 (4): 528-529.

10. King HK, Wang LF, Khan AK: A modification of laryngoscopy technique. Anaesthesiology 1986; 65: 566.

11. Samsoon GLT, Young JRB: Difficult tracheal intubation: a retrospective study. Anaesthesia 1987; 42: 487-490.

12. Mc Intyre J WR: Laryngoscope designed the difficult adult intubation. Canadian Journal of Anaesthesia 1989; 36 (1): 94-98.

13. Davies JM, Crone LA, Weeks S, Pavlin E: Difficult intubation in the parturient. Canadian Journal of Anaesthesia 1989; 36 (6): 668-674.

14. Dupont X, Hamza J, Jullien P, Narchi P: Risk factors associated with difficult airway in normotensive parturient. Anaesthesiology 1990; a 999.

15. King TA, Adams AP: Failed tracheal intubation. British Journal of Anaesthesia 1990; 65: 400414.

16. Cobley M, Vaughan RS: Recognition and management of difficult airway problems. British Journal of Anaesthesia 1992; 68: 90-97.

17. Rocke DA, Murray WB, and Rout CC, Gouwes E: Relative risk analysis of factors associated with difficult intubation in obstetric anaesthesia. Anaesthesiology 1992; 77: 67-73.

18. Report by American Society of Anaesthesiologists Task Force: Practice guidelines for management of the difficult airway. Anaesthesiology 1993; 78: 597-602.

19. Pilkington S, Carli F, Dakin MJ, Romney M, De Witt KA, Dore CJ, and Cormack RS: Increase in Mallampati score during pregnancy. British Journal of Anaesthesia 1995; 74: 638-642.

20. Ramadhani SAL, Mohamed LA, Rocke DA, Gouws E: Sternomental distance as the sole predictor if difficult laryngoscopy in obstetric Anaesthesia. British Journal of Anaesthesia 1996; 77: 312316.

21. Barnardo PD, Jenkins JG: Failed tracheal intubation in obstetrics. Anaesthesia 2000: 55: 685694.

22. Burkle CM, Zepeda FA, Bacon DR, Rose SH: A historical perspective on use of the laryngoscope as a tool in Anaesthesiology. Anaesthesiology 2004; 100: 1003-1006.

23. Cooper RM: Laryngoscopy - it's past and future. Canadian Journal of Anaesthesia 2004; 51: R6.

24. Rudra A: Airway management in obstetrics. Indian Journal of Anaesthesia 2005; 49(4): 328335.

25. Jack EM, Loren AC: Doctor, which type of blade do you want to use now? American Journal of Clinical Medicine 200515-19. 


\section{ORIGINAL ARTICLE}

\section{AUTHORS:}

1. Neeharika

\section{PARTICULARS OF CONTRIBUTORS:}

1. Assistant Professor, Department of Anaesthesiology, SRMSIMS, Bareilly.
NAME ADDRESS EMAIL ID OF THE

\section{CORRESPONDING AUTHOR:}

Dr. Neeharika, \# 8B, Model Town,

Bareilly.

Email: docneehars@gmail.com

Date of Submission: 03/09/2014.

Date of Peer Review: 04/09/2014.

Date of Acceptance: 11/09/2014.

Date of Publishing: 18/09/2014. 